\title{
Knockdown of RNF2 induces cell cycle arrest and apoptosis in prostate cancer cells through the upregulation of TXNIP
}

\author{
Ming Wei, ${ }^{1, *}$, Dian Jiao', ${ }^{1, *}$, Donghui Han ${ }^{3}$, Jieheng $\mathbf{W u}^{2}$, Feilong $\mathbf{W e i}^{2}$, Guoxu Zheng ${ }^{2}$, \\ Zhangyan Guo ${ }^{2}$, Wenjin $\mathrm{Xi}^{2}$, Fa Yang ${ }^{3}$, Pin $\mathrm{Xie}^{3}$, Lingling Zhang ${ }^{2}$, An-Gang Yang ${ }^{2}$, \\ He Wang ${ }^{1}$, Weijun Qin ${ }^{3}$, Weihong Wen ${ }^{2}$ \\ ${ }^{1}$ Department of Urology, Tangdu Hospital, Fourth Military Medical University, 710038 Xi'an, China \\ ${ }^{2}$ State Key Laboratory of Cancer Biology, Department of Immunology, Fourth Military Medical University, 710032 Xi'an, China \\ ${ }^{3}$ Department of Urology, Xijing Hospital, Fourth Military Medical University, 710032 Xi'an, China \\ * Co-first author \\ Correspondence to: Weihong Wen, email: wenweih@fmmu.edu.cn \\ Weijun Qin, email: qinweij@fmmu.edu.cn
}

Keywords: RNF2, TXNIP, prostate cancer, cell cycle, apoptosis

Received: June 03, $2016 \quad$ Accepted: November 22, $2016 \quad$ Published: December 24, 2016

\section{ABSTRACT}

RNF2, also known as RING1b or RING2, is identified as the catalytic subunit of polycomb repressive complex 1 (PRC1), which mediates the mono-ubiquitination of histone H2A. RNF2 has been proved to have oncogenic function in many kinds of cancers, but the function of RNF2 in prostate cancer (PCa) has not been evaluated. Here we show that PCa tissues showed higher RNF2 expression than the benign prostatic hyperplasia (BPH) tissues. Knockdown of RNF2 in PCa cells resulted in cell cycle arrest, increased apoptosis and inhibited cell proliferation, and the growth of RNF2 knockdown PCa xenografts were obviously inhibited in nude mice. Gene microarray analysis was performed and tumor suppressor gene TXNIP was found to be significantly increased in RNF2 knockdown cells. Simultaneously knockdown of RNF2 and TXNIP can partially rescue the arrested cell cycle, increased apoptosis and inhibited cell proliferation in RNF2 single knockdown cells. Furthermore, ChIP assay result showed that RNF2 enriched at the TXNIP promoter, and the enrichment of RNF2 and ubiquitination of H2A in TXNIP promoter was obviously inhibited in RNF2 knockdown cells. In conclusion, our results demonstrate that RNF2 functions as an oncogene in PCa and RNF2 may regulate the progression of PCa through the inhibition of TXNIP.

\section{INTRODUCTION}

Prostate cancer (PCa) is the most common malignancy and the second leading cause of cancer death in men, which causes 913,000 new cases and over 261,000 deaths worldwide each year [1]. Early stage PCa can be cured by surgery or radiation, but advanced $\mathrm{PCa}$ is not curable. Generally, systemic androgen ablation is the mainstay of therapy for disseminated PCa, which aims to suppress the androgen receptor (AR) mediated survival signaling. Unfortunately, inhibition of androgen function, together with or without cytotoxic chemotherapy, is only palliative, but not curative. Until now there have no validated molecular targets for PCa. Therefore, the identification of novel therapeutic targets and the development of new strategies for the treatment of $\mathrm{PCa}$ are urgently required.

Epigenetic regulation, including DNA methylation, histone modifications and chromatin remodeling, play important roles in the initiation and development of different cancer types, including PCa [2, 3]. Function study of the epigenetic regulators, not only can imply a causative role for these proteins in cancer development but also can provide potential targets for cancer therapy. Several small molecule 
inhibitors targeting DNA methyltransferases (DNMTs), histone deacetylases (HDACs) and janus kinase 2 (JAK2) have already been granted approval by the US Food and Drug Administration (FDA) for the treatment of certain cancers [4-6]. Thus, the identification of key epigenetic mechanisms in cancer progression may provide new indications for the development of new therapeutic strategies.

Polycomb group (PcG) proteins have been identified as important epigenetic regulators that are involved in embryonic development, tissue homeostasis, stem cell self-renewal and cancer development and progression [7-10]. PcG proteins exist in multimeric complexes, and there have two main complexes in mammals, called polycomb repressive complex 1 (PRC1) and PRC2 respectively. PRC1 is composed of Polycomb (Pc), polyhomeotic (PH), Bmil, Ring1a and RNF2 (Ring1b), while PRC2 mainly contains EZH2, EED, and SUZ12 [11-13]. Several PcG proteins have been shown to have oncogenic function and have been demonstrated to be highly expressed in certain cancer types, including PCa [14]. EZH2, which is the catalytic subunit of PRC2, has been shown to be overexpressed in metastatic PCa and high EZH2 level is correlated with poor prognosis [15]. The oncogenic function of EZH2 in castration-resistant prostate cancer indicated that it can be used as a therapeutic target $[16,17]$. Bmil, which is component of PRC1, has also been shown to have higher expression than normal prostatic epithelial cells and PIN, and overexpression of Bmil formed significantly larger tumors in NOD/SCID mice [18].

RNF2 is the catalytic subunit of PRC1. RNF2 has also been found to be highly expressed in large series of cancer types including breast cancer, ovarian cancer, pancreatic cancer, bladder cancer, melanoma, lymphoma, et al. And high expression of RNF2 is positively correlated with tumor progression and shortened survival, thus RNF2 is considered to be a prognostic biomarker and potential therapeutic target for these cancer types [19-22]. RNF2 has also been shown to be highly expressed in $\mathrm{PCa}$ compared with normal tissues [19], yet whether RNF2 plays an oncogenic function in $\mathrm{PCa}$ and the potential mechanism is not clear.

The goal of this study is to investigate the function of RNF2 in PCa and to explore the potential mechanism. In this paper, we showed that RNF2 is highly expressed in $\mathrm{PCa}$ tissues than the benign prostatic hyperplasia (BPH) tissues, and knockdown of RNF2 in PCa cells resulted in cell cycle arrest, increased apoptosis and inhibited cell proliferation. The oncogenic function of RNF2 was also confirmed in PCa xenograft nude mice. Furthermore, we identified that thoredoxin interacting protein (TXNIP) is a functional target of RNF2. RNF2 is enriched in the promoter of TXNIP, and RNF2 may regulate TXNIP expression through the ubiquitination on histone $\mathrm{H} 2 \mathrm{~A}$.

\section{RESULTS}

\section{PCa tumor tissues showed higher RNF2 expression than BPH tissues}

To evaluate the expression status of RNF2 in PCa, IHC staining was performed on two tissue microarray sections including $81 \mathrm{PCa}$ tissues and $71 \mathrm{BPH}$ tissues. Results showed that PCa tissues have obviously higher RNF2 expression than the BPH tissues, with the $\mathrm{H}$-Score of $117.53 \pm 62.34$ and $90.14 \pm 63.66$, respectively $(p<0.05$, Figure 1A, 1B). The RNF2 expression level was also analyzed with $\mathrm{PCa}$ tumor grade, and results showed that the RNF2 expression was significantly higher in high grade $\mathrm{PCa}($ Gleason $>7)$ (H-Score: $150.5 \pm 62.03)$ than low grade $\mathrm{PCa}($ Gleason $\leq 7)$ (H-Score: 97.10 \pm 53.63$)$ (Figure 1C). These results indicate that PCa tissues have higher RNF2 expression than BPH tissues, and the RNF2 level is positively correlated with tumor grade, indicating that RNF2 may have an oncogenic function in PCa.

\section{Knockdown of RNF2 resulted in cell cycle arrest and apoptosis in DU145 and LNCaP cells}

To evaluate the biological function of RNF2 in $\mathrm{PCa}$, the expression of RNF2 was knocked down in DU145 and LNCaP cells by siRNAs. The knockdown efficiency was confirmed by RT-qPCR and western blot (Figure 2A, 2B). Cell cycle and apoptosis were analyzed by flow cytometry, and results showed that obvious G1 phase arrest and obvious apoptosis were induced in RNF2 knockdown cells, compared with the control cells (Figure 2C, 2D). The cell proliferation was evaluated using MTT assay, and results show that the proliferation of RNF2 knockdown cells were dramatically inhibited compared with the control cells (Figure 2E). These results indicate that RNF2 plays an important role in the regulation of cell cycle and apoptosis in PCa cells.

\section{Knockdown of RNF2 inhibited the growth of PCa xenograft in nude mice}

To evaluate whether knockdown of RNF2 can inhibit PCa tumor growth in vivo, we knocked down RNF2 expression using shRNA expressing lentivirus in DU145 cells. The knockdown efficiency of shRNA was confirmed by RT-qPCR and western blot (Figure 3A, 3B). Cell cycle, apoptosis and cell proliferation were also evaluated in lentivirus infected DU145 cells, and shRNF2 lentivirus infected cells also showed obviously G1 arrest, increased apoptosis and inhibited cell proliferation (Supplementary Figure S1A, S1B and S1C). Then, the RNF2 knockdown (shRNF2 \#1 and shRNF2 \#2) and control DU145 cells (shScr) were inoculated into athymic nude mice. Tumor 

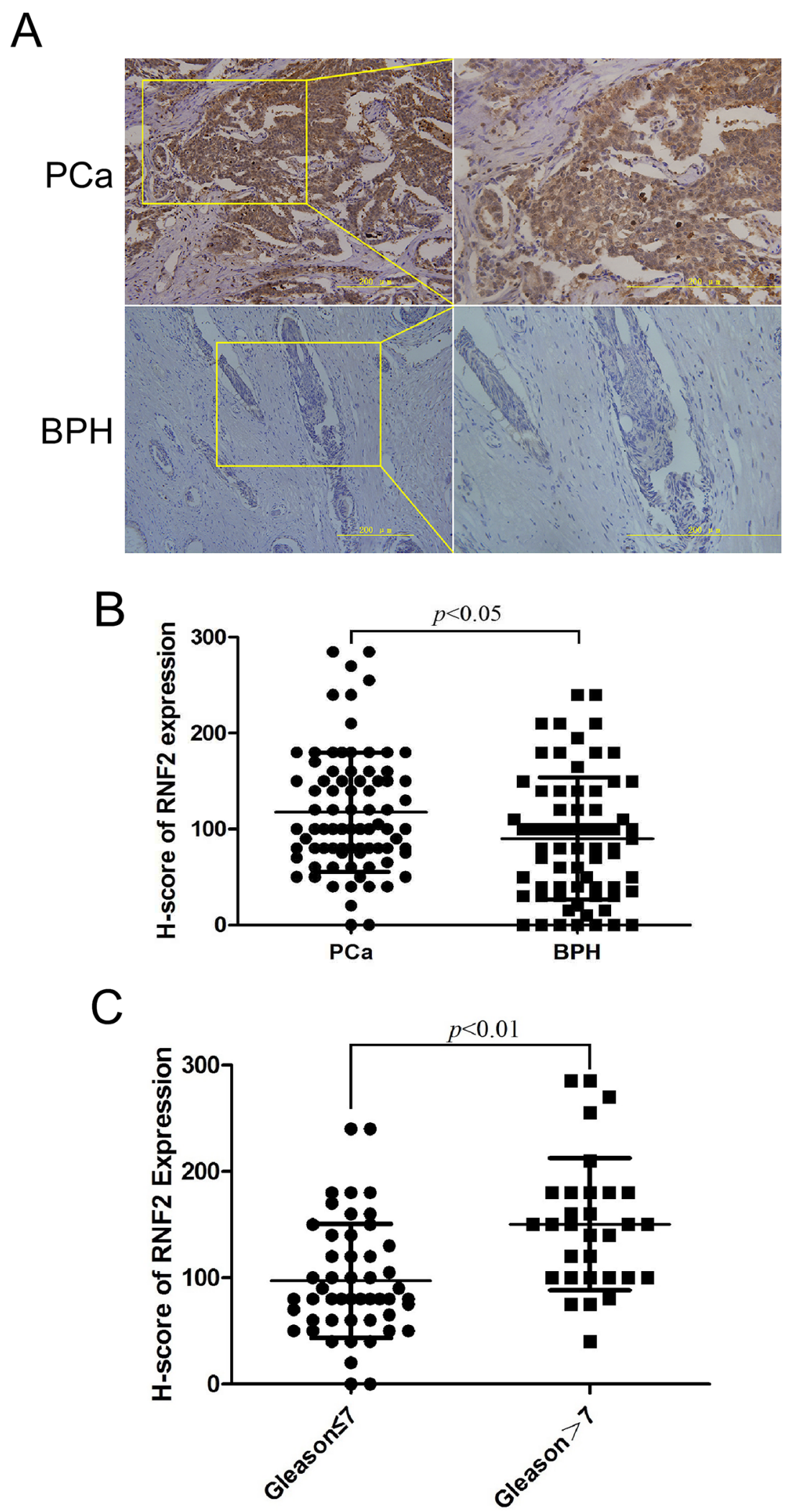

Figure 1: PCa tumor tissues showed higher RNF2 expression than BPH tissues. A. Representative IHC staining to show RNF2 expression in PCa and BPH tissues. The brown color indicates the positive expression of RNF2. Right pictures are the magnified view of the yellow box in the left. Scale bar: $200 \mu \mathrm{m}$. B. Statistical analysis of H-score of RNF2 expression in PCa and BPH tissues. C. Statistical analysis of H-score of RNF2 expression in low and high grade PCa. 
growth was observed from day 0 to day 35 after inoculation. Results show that the tumor growth in RNF2 knockdown group (shRNF2 \#1 and shRNF2 \#2) was dramatically inhibited compared with the control (shScr) group, with the final tumor volume of $304.33 \pm 63.72 \mathrm{~mm}^{3}$, $331.93 \pm 84.42 \mathrm{~mm}^{3}$ and $846.80 \pm 55.29 \mathrm{~mm}^{3}$, respectively $(p<0.05$, Figure $3 \mathrm{C})$. To evaluate the difference of the cell proliferation and apoptosis in RNF2 knockdown
A

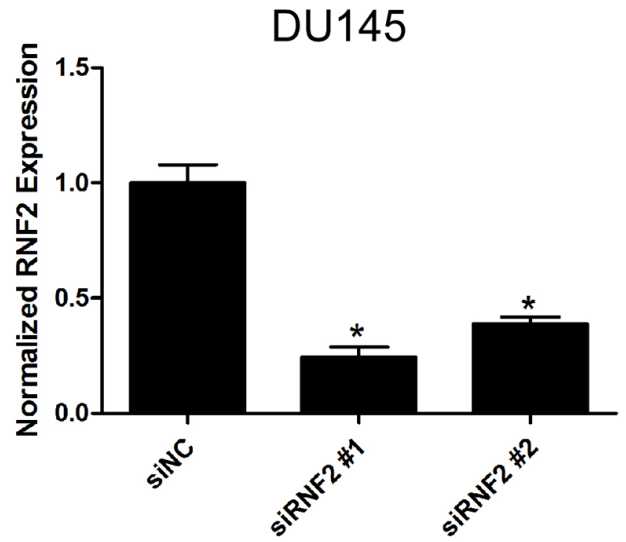

B

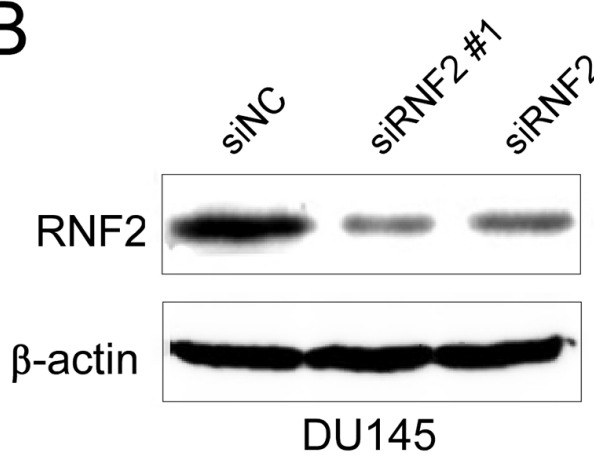

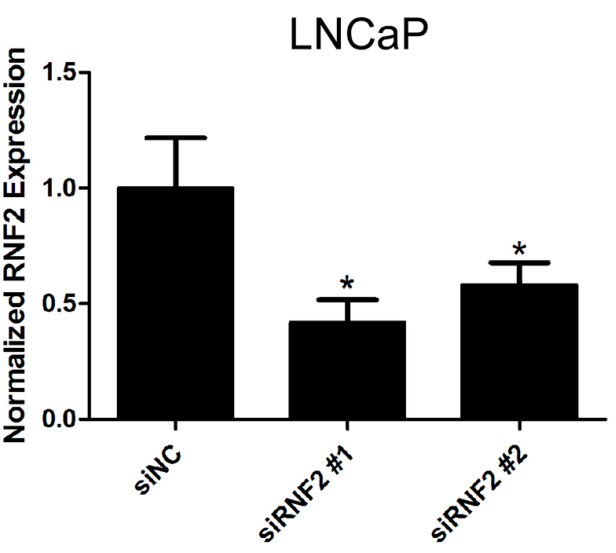
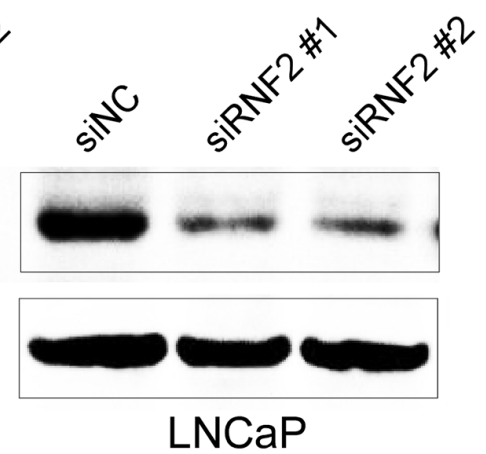

C
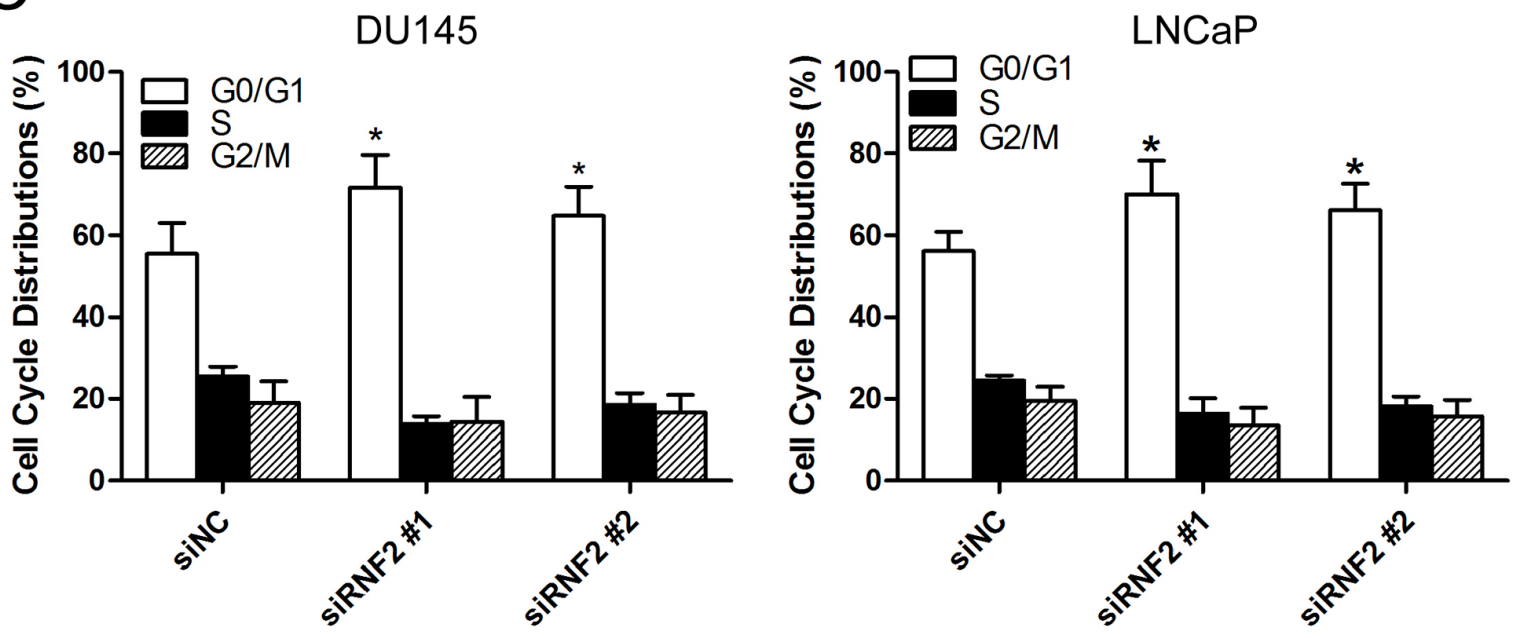

Figure 2: Knockdown of RNF2 resulted in cell cycle arrest and apoptosis in DU145 and LNCaP cells. A. RT-qPCR analysis to show the knockdown efficiency of RNF2 in DU145 and LNCaP cells transfected with siRNA. ${ }^{*} p<0.05$ versus siNC. B. Western blot analysis to show the knockdown efficiency of RNF2 in DU145 and LNCaP cells transfected with siRNA. C. Cell cycle analysis of the RNF2 knockdown and control DU145 and LNCaP cells. Data are shown as the mean \pm S.D. from three independent experiments. ${ }^{*} p<0.05$ versus siNC. (Continued) 
$\mathrm{D}$

DU145
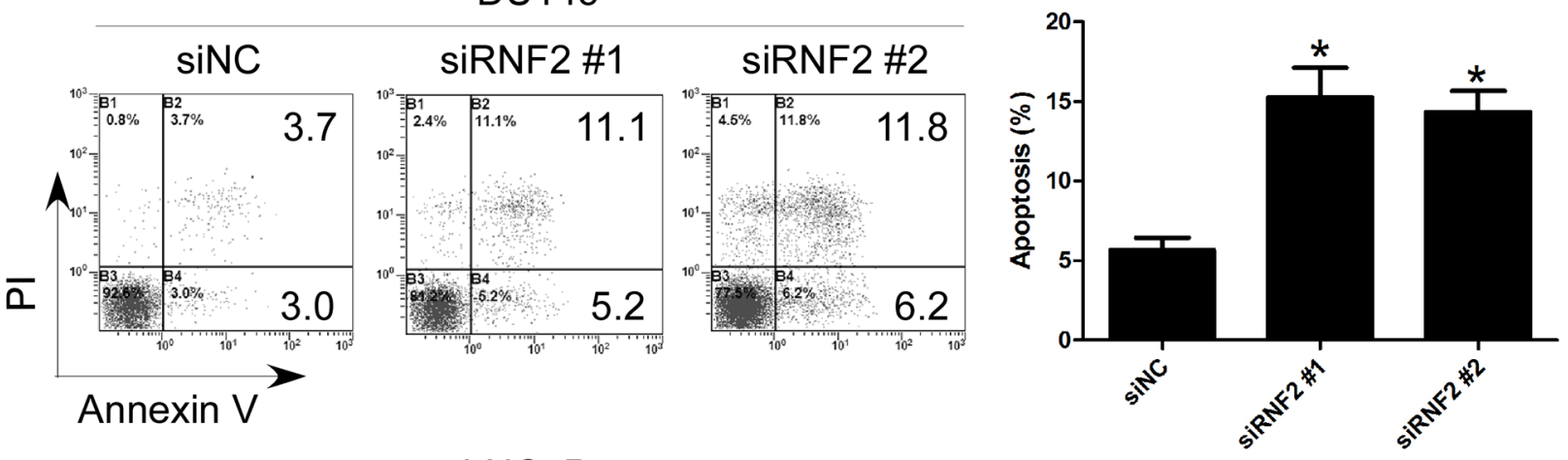

LNCaP

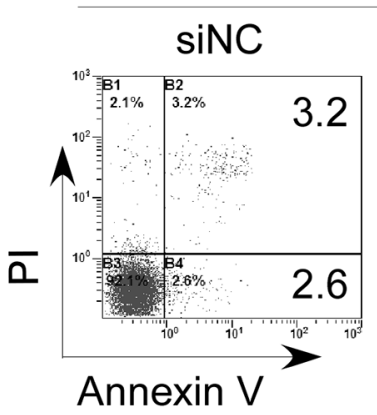

siRNF2 \#1
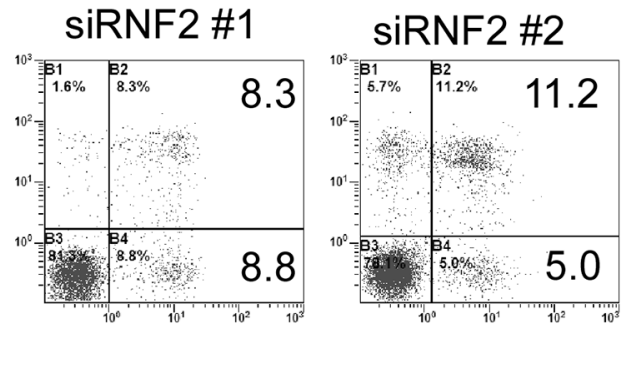

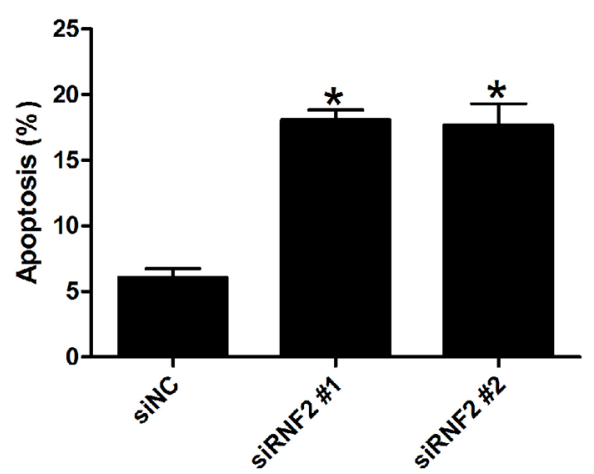

$E$

DU145

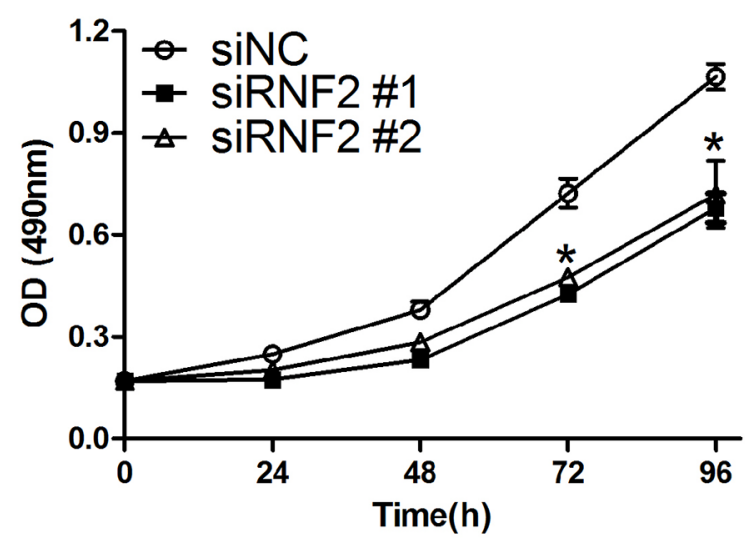

LNCaP

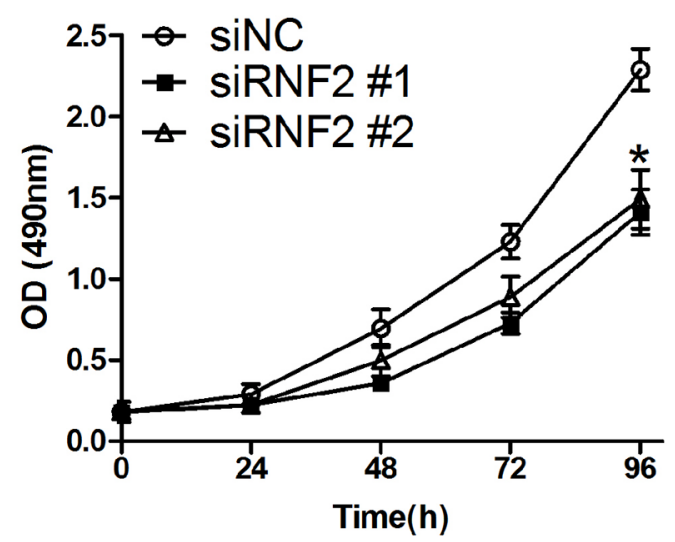

Figure 2: (Continued) Knockdown of RNF2 resulted in cell cycle arrest and apoptosis in DU145 and LNCaP cells. D. Apoptosis analysis of the RNF2 knockdown and control DU145 and LNCaP cells. Data are representative of three independent experiments. ${ }^{*} p<0.05$ versus siNC. E. MTT assay to show the cell proliferation of RNF2 knockdown and control DU145 and LNCaP cells. Data are shown as mean \pm S.D. from three independent experiments. ${ }^{*} p<0.05$ versus siNC.

and control xenograft tumor tissues, IHC staining were performed to detect the level of proliferating cell nuclear antigen (PCNA) and cleaved caspase-3. Results show that the RNF2 knockdown tumor tissue had decreased PCNA level while increased cleaved caspase-3 level than the control tissues (Figure 3D). These results indicate that knockdown of RNF2 can effectively inhibit tumor growth in nude mice through inhibiting cell proliferation and promoting apoptosis. Thus, our data demonstrate that RNF2 has an oncogenic function in PCa. 

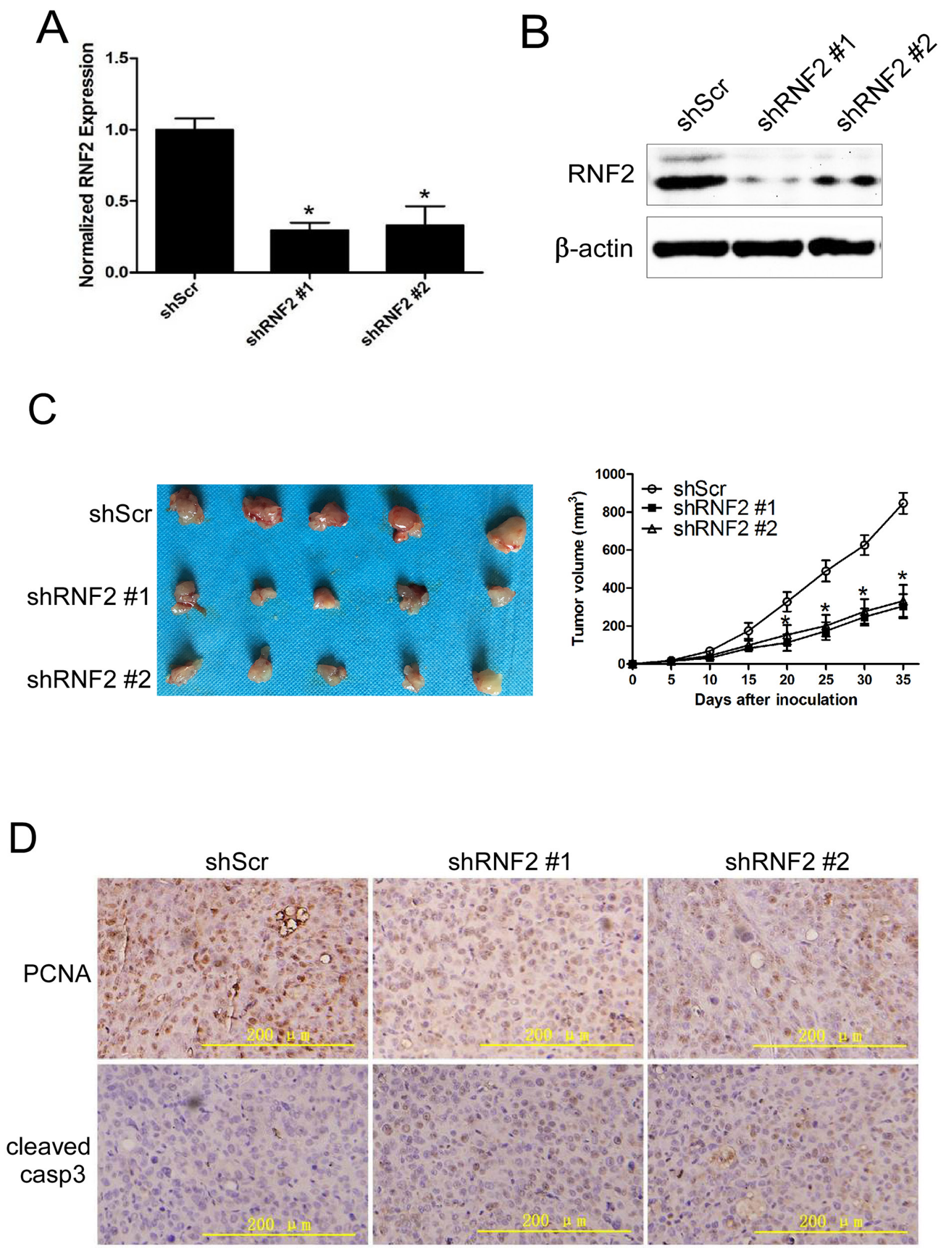

Figure 3: Knockdown of RNF2 inhibited the growth of PCa xenograft in nude mice. A. RT-qPCR analysis to show the knockdown efficiency of RNF2 in DU145 cells by shRNA expressing lentivirus. * $p<0.05$ versus shScr. B. Western blot analysis to show knockdown efficiency of RNF2 in DU145 cells by shRNA expressing lentivirus. * $p<0.05$ versus shScr. C. Tumor growth curve of the RNF2 knockdown and control DU145 xenografts in vivo. Data are shown as the mean \pm S.D., ${ }^{*} p<0.05$ versus shScr. D. IHC staining to show the level of PCNA and cleaved caspase-3 in RNF2 knockdown and control DU145 xenograft tumor tissues. The brown color indicates the positive expression of PCNA and cleaved caspase-3. Scale bar: $200 \mu \mathrm{m}$. 


\section{TXNIP expression was increased in RNF2 knockdown PCa cells}

To explore the mechanism how RNF2 regulates cell proliferation and apoptosis in $\mathrm{PCa}$, we performed microarray analyses using the mRNA from RNF2 knockdown and control DU145 cells. Using a 1.5 fold cutoff, we found that 632 genes were differentially expressed in RNF2 knockdown cells. Of these genes, 144 were upregulated and 488 were downregulated. Some of the most significantly changed genes, which participate in the regulation of cell cycle, apoptosis and proliferation, are shown in Figure 4A. Considering the transcriptional repressive function of $\mathrm{PcG}$ proteins, we mainly focused on the tumor suppressor genes that were increased in RNF2 knockdown cells, among which, TXNIP is one of the most significantly increased genes. The increased TXNIP expression was confirmed in RNF2 knockdown DU145 and LNCaP cells in both mRNA and protein levels (Figure 4B, 4C, Supplementary Figure S2A, $\mathrm{S} 2 \mathrm{~B})$. The expression level of TXNIP was also examined by IHC in RNF2 knockdown DU145 xenograft tumor tissues, and results showed that RNF2 knockdown group had increased TXNIP level than the control group (Figure 4D). Taken together, these results indicate that TXNIP might be one of the functional target genes that are repressed by RNF2.

\section{Simultaneously knockdown of TXNIP partially rescue the phenotype in RNF2 single knockdown cells}

To find out whether TXNIP is a functional downstream target of RNF2 in PCa cells, rescue experiments were performed by simultaneously knockdown RNF2 and TXNIP in DU145 and LNCaP cells by either shRNA expressing lentiviruses or siRNA. The knockdown efficiency were confirmed by RT-qPCR and Western blot (Figure 5A, 5B, Supplementary Figure S3A, S3B). Cell cycle and apoptosis were evaluated in RNF2 and/or TXNIP knockdown cells. Results show that simultaneous knockdown of RNF2 and TXNIP can partially rescue the increased G1 phase and apoptosis in RNF2 single knockdown cells (Figure 5C, 5D, Supplementary Figure S3C, S3D). MTT assay was performed to evaluate cell proliferation, and results showed that simultaneously knockdown of RNF2 and TXNIP can rescue the inhibited cell proliferation in RNF2 single knockdown cells (Figure 5E, Supplementary Figure S3E). These results demonstrate that TXNIP is an important downstream molecule in RNF2 mediated regulation of cell proliferation, cell cycle and apoptosis in PCa cells.

\section{Knockdown of RNF2 decreased the enrichment of RNF2 and H2AK119Ub at the TXNIP promoter}

To further explore the potential mechanism how RNF2 regulates TXNIP expression, we performed ChIP assay to examine whether RNF2 may directly bind at the TXNIP promoter and mediate $\mathrm{H} 2 \mathrm{~A}$ ubiquitination. Anti-RNF2 and anti-H2AK119Ub antibodies were used for ChIP assay and three pairs of primers were designed to amplify a specific region within 1000 bp upstream of the transcription start site of TXNIP (Figure 6A). Results show that RNF2 and ubiquitinated H2A can be specifically enriched in the TXNIP promoter (Figure 6B). And when RNF2 was knocked down, the enrichment of both RNF2 and ubiquitinated $\mathrm{H} 2 \mathrm{~A}$ were inhibited (Figure $6 \mathrm{C}$ ). These results indicate that RNF2 can bind at the promoter of TXNIP and regulates H2A ubiquitination, thus inhibits its expression. We concluded that RNF2 may regulates $\mathrm{PCa}$ cell proliferation, apoptosis and cell cycle through direct regulation on TXNIP.

\section{DISCUSSION}

Epigenetic regulation plays important roles not only in normal development but also in different kinds of diseases, including cancer. Among different epigenetic mechanisms, histone post-translational modifications, such as acetylation, methylation and ubiquitination were most intensely studied in recent years [4, 5, 23, 24].

The polycomb group (PcG) proteins are important epigenetic regulators that are involved in the regulation of histone modification. PcG proteins work as transcriptional repressors and play important roles in several developmental and physiological processes. Several PcG proteins such as EZH2 and Bmil have been found to play important roles in cancer development and progression, including PCa [25-27]. And certain genes have been identified to be the targets of PcG proteins and the repressed expression of these genes is associated with poor prognosis in $\mathrm{PCa}$ [28-30].

RNF2 is the catalytic subunit of PRC1 complex, which is responsible for the mono-ubiquitination of histone H2A. It has been reported that RNF2 has very low expression in normal tissues, but has high expression in certain cancer types. RNF2 has been considered to be a prognostic biomarker and potential therapeutic target for these cancer types [19-22]. In melanoma, RNF2 has been shown to be oncogenic and prometastatic, and RNF2 can promote metastasis through the inhibition of LTBP2, while its oncogenic function does not require it catalytic activity and RNF2 promotes cell proliferation through direct transcriptional upregulation of CCND2 [31]. Recently, it has been reported that RNF2 can regulate p53 stability through either direct ubiquitination or promoting MDM2 mediated ubiquitination in certain cancer types, providing a possible mechanism how RNF2 function as an oncogene $[32,33]$. Despite these findings, the function of RNF2 in $\mathrm{PCa}$ is still not clear.

In this study, we found that $\mathrm{PCa}$ tissues have much higher RNF2 expression than BPH tissues, and RNF2 expression is positively correlated with tumor grade, 
A

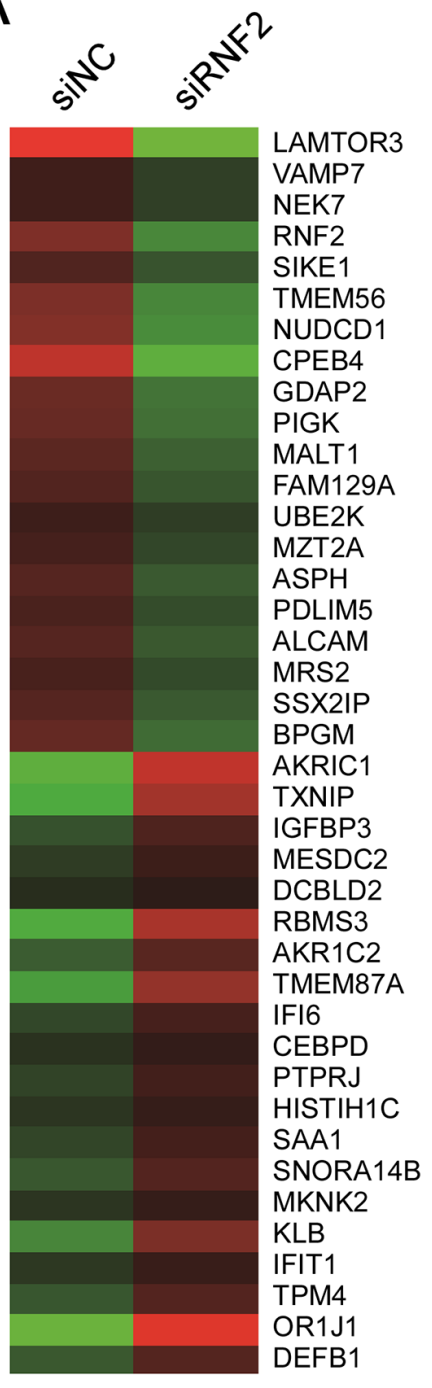

\section{B}
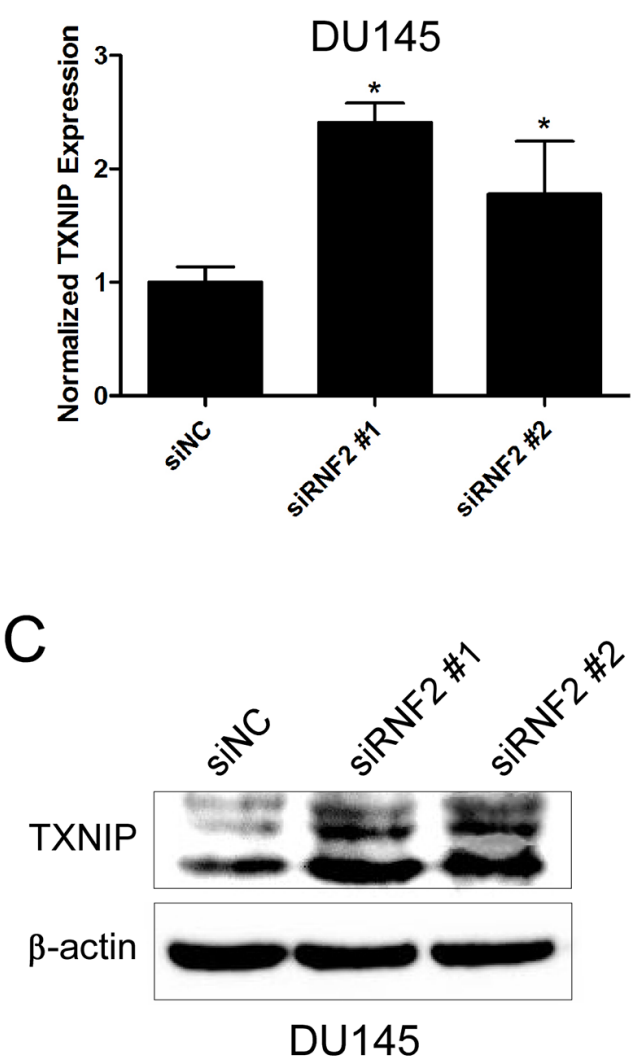

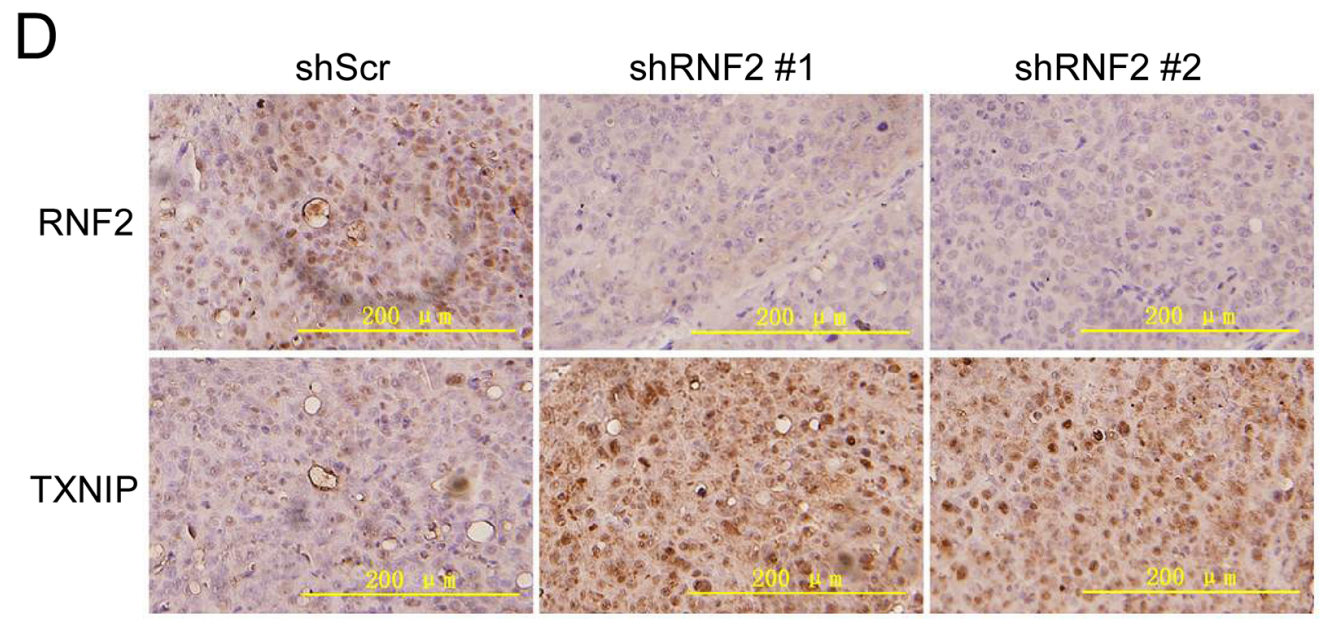

Figure 4: TXNIP expression was increased in RNF2 knockdown DU145 cells. A. Heat map of the most differentially expressed genes in siNC and siRNF2 cells by microarray analyses (Red: upregulated; Green: downregulated). B. RT-qPCR analysis to show the increased TXNIP mRNA level in RNF2 knockdown DU145 cells. ${ }^{*} p<0.05$ versus siNC. C. Western blot analysis to show the increased TXNIP protein level in RNF2 knockdown DU145 cells. ${ }^{*} p<0.05$ versus siNC. D. Representative IHC staining to show the increased TXNIP expression in RNF2 knockdown DU145 xenografts. The brown color indicates the positive expression of RNF2 and TXNIP. Scale bar: $200 \mu \mathrm{m}$. 

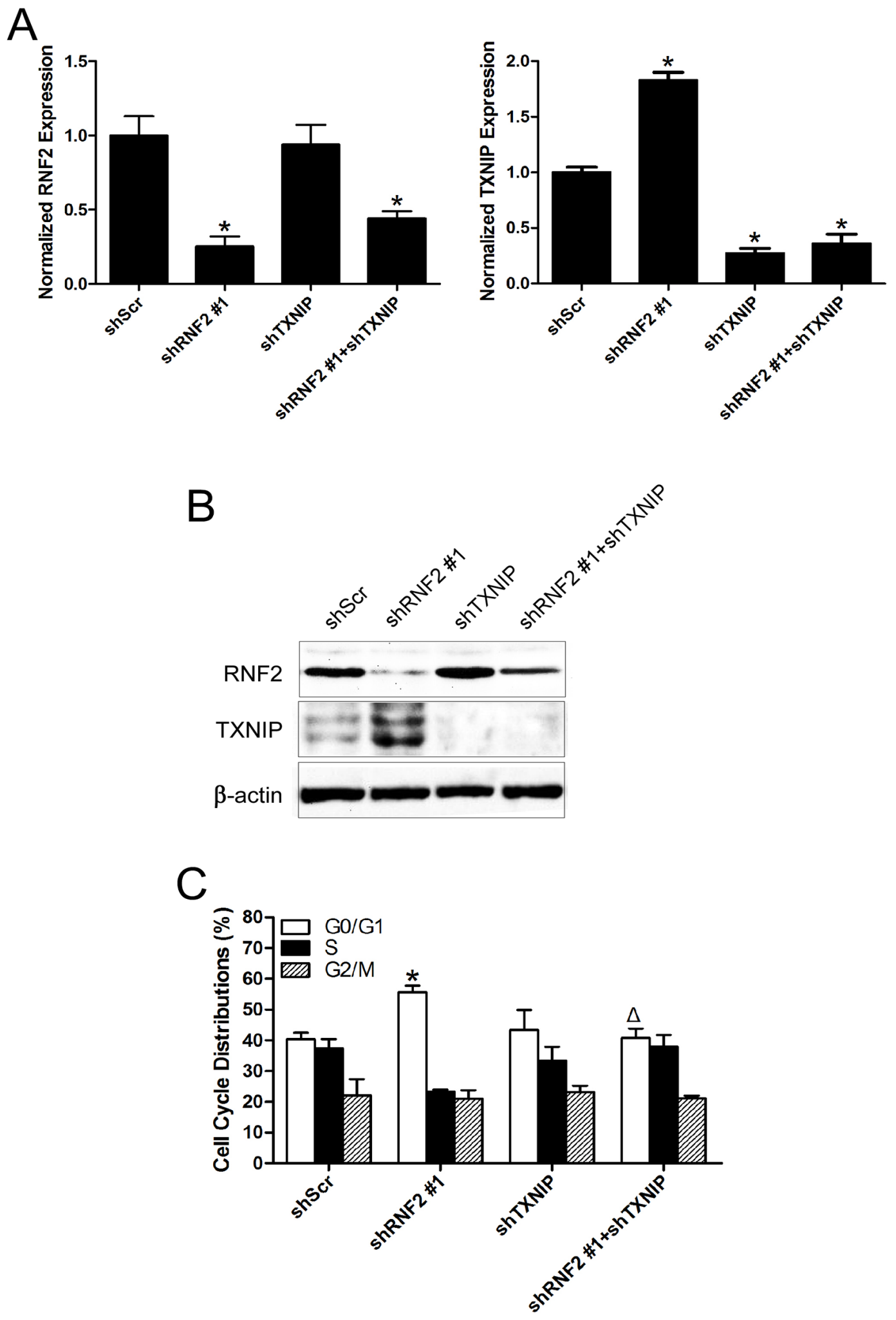

Figure 5: Simultaneously knockdown of TXNIP can partially rescue the phenotype in RNF2 single knockdown DU145 cells. A. RT-qPCR analysis to show the efficient inhibition of RNF2 and TXNIP mRNA level in DU145 cells infected with shRNA expressing lentivirus. B. Western blot analysis to show the efficient knockdown of RNF2 and TXNIP expression in DU145 cells infected with shRNA expressing lentivirus. C. Cell cycle analysis in RNF2 and/or TXNIP knockdown and control DU145 cells. Data are shown as the mean \pm S.D. from three independent experiments. (Continued) 

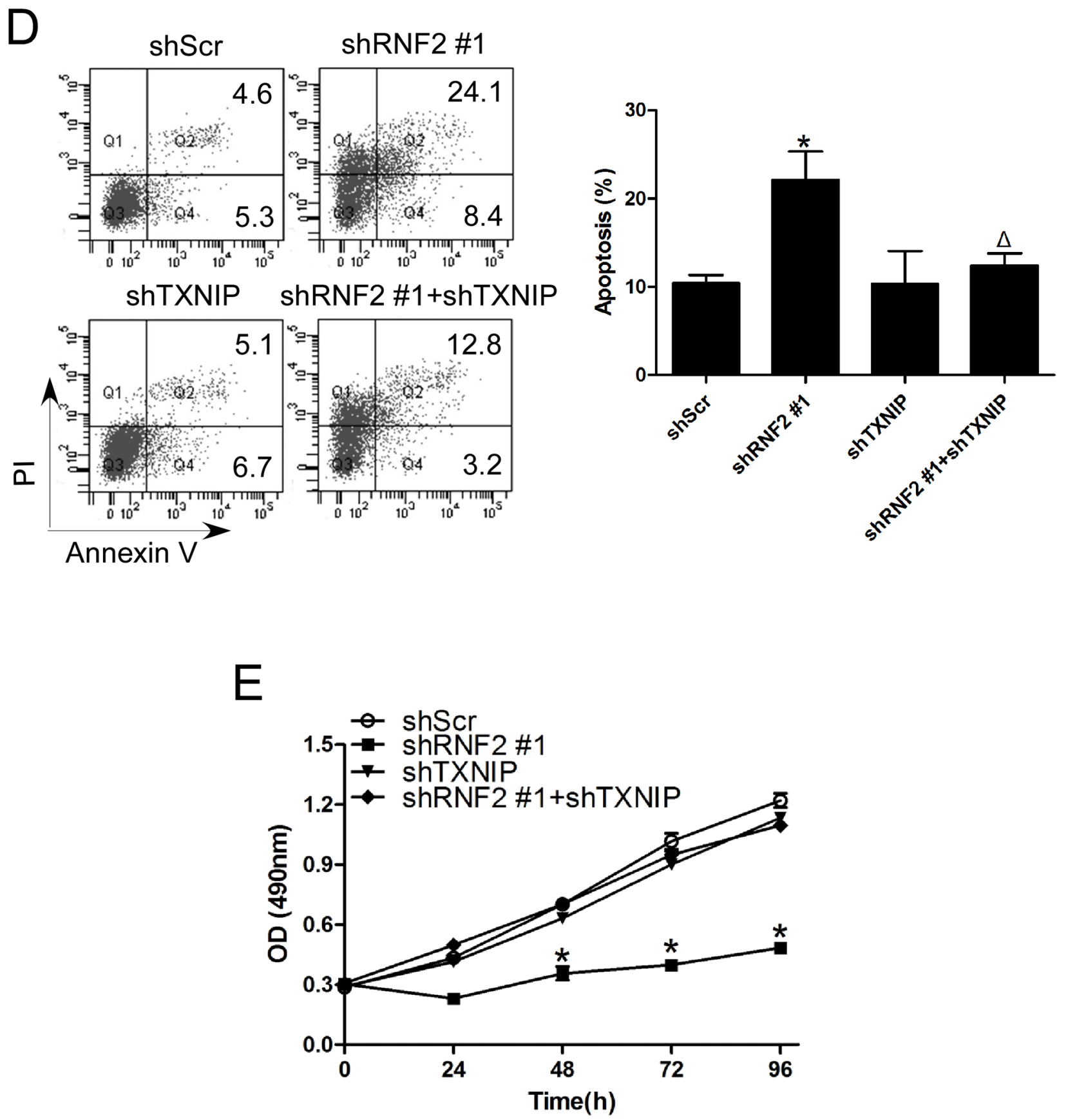

Figure 5: (Continued) Simultaneously knockdown of TXNIP can partially rescue the phenotype in RNF2 single knockdown DU145 cells. D. Apoptosis analysis in RNF2 and/or TXNIP knockdown and control DU145 cells. Data are representative of three independent experiments. E. MTT assay to show the cell proliferation in RNF2 and/or TXNIP knockdown and control DU145 cells. Data are shown as the mean \pm S.D. from three independent experiments. ${ }^{*} p<0.05$ versus shScr, $\Delta p<0.05$ versus shRNF2 $\# 1$.

indicating that RNF2 may have oncogenic function in $\mathrm{PCa}$. We further explored the function of RNF2 in PCa cells using siRNA or shRNA, and found that knockdown of RNF2 resulted in cell cycle arrest, increased apoptosis and inhibited cell proliferation in DU145 and LNCaP cells. In addition, RNF2 knockdown DU145 xenografts showed significantly inhibited tumor growth in nude mice. These results are consistent with other reports, which showed that RNF2 participates in the regulation of cell proliferation, cell cycle and apoptosis [20, 22, 32, 34, 35].

To elucidate the underlying mechanism how RNF2 functions as an oncogene in $\mathrm{PCa}$, we performed microarray analysis using RNA from RNF2 knockdown and control DU145 cells. Plenty of genes were found to be differentially expressed in RNF2 knockdown and control cells. Based on the phenomenon that RNF2 exert 
an oncogenic function and can suppress gene expression, we mainly focused on several tumor suppressor genes. We identified that the expression of tumor suppressor gene TXNIP was significantly increased in RNF2 knockdown cells. To ensure that TXNIP is a functional downstream target, rescue experiments were performed,

A
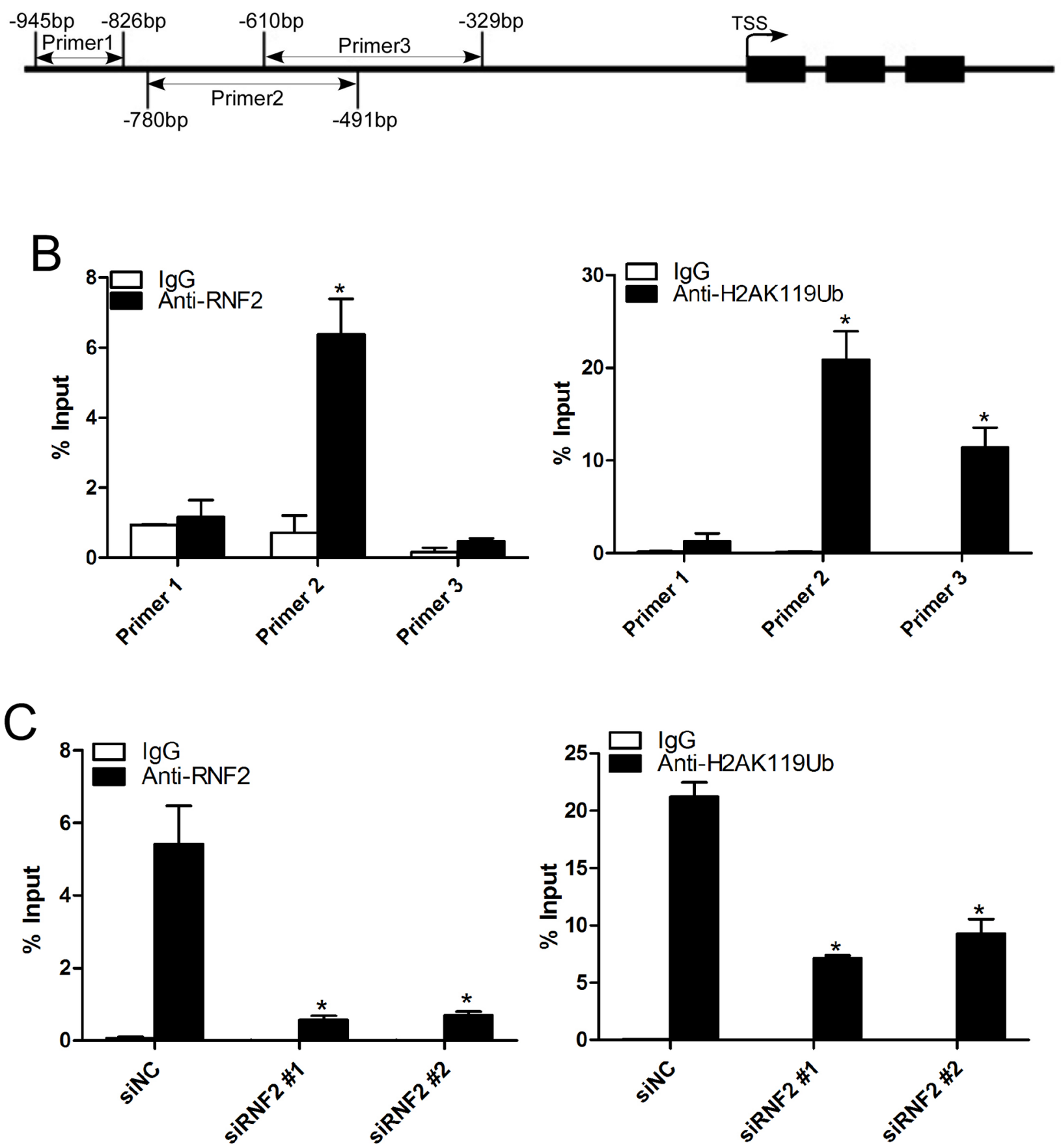

Figure 6: Knockdown of RNF2 decreased the enrichment of RNF2 and H2AK119Ub at the TXNIP promoter. A. The illustrative picture to show the regions of the PCR products used in ChIP assays. B. Quantitative PCR analyses of the ChIP assays using antibodies against RNF2 and H2AK119Ub. Data are shown as mean \pm S.D. from three independent experiments. ${ }^{*} p<0.05$ versus IgG. C. Quantitative PCR analyses using primer 3 to show the enrichment of RNF2 and H2AK119Ub at the TXNIP promotor in RNF2 knockdown and control DU145 cells. Data are shown as mean \pm S.D. from three independent experiments. * $p<0.05$ versus siNC. 
and results showed that simultaneously knockdown of TXNIP can partially rescue the inhibited cell proliferation, increased apoptosis and arrested cell cycle in RNF2 single knockdown cells. These results support the conclusion that TXNIP is a functional downstream target of RNF2. Using TCGA data, we also analyzed the TXNIP expression in $\mathrm{PCa}$, and found that the TXNIP expression is significantly decreased in PCa than normal tissues, and the TXNIP expression is inversely correlated with the RNF2 expression in PCa (data not shown).

TXNIP, also known as Vitamin D3 up-regulated protein 1 (VDUP-1) or thioredoxin binding protein 2 (TBP-2), is a key regulator of the redox system, and has been identified as a tumor suppressor $[36,37]$. TXNIP is frequently downregulated in many types of human cancers, such as breast cancer, colon cancer, lung cancer, et al [38-42]. TXNIP has been shown to be regulated through epigenetic modification during cancer development, such as DNA methylation and histone deacetylation [43, 44]. TXNIP has also been demonstrated to be the target of PRC2, and the PRC2 inhibitor, 3-Deazaneplanocin A (DZNep), can preferentially induce apoptosis in cancer cells through the induction of TXNIP $[45,46]$. The upregulation of TXNIP expression and subsequent induction of apoptosis have also been shown to be the mechanism of the anti-tumor effect by various agents such as anisomycin, oxidative stress, dexamethasone, PPAR $\gamma$, calcium influx and potassium ion [47-50].

In our study, to explore the mechanism how RNF2 regulates TXNIP expression, we performed ChIP assays, and found the RNF2 enriches at TXNIP promoter and induce the ubiquitination of $\mathrm{H} 2 \mathrm{~A}$ at K119, which has been shown to be critical for PRC1-dependent repression of target genes [51]. The RNF2 mediated H2A ubiquitination can be inhibited by Aurora B mediated histone H3S28 phosphorylation, resulting in the transcription of active genes in resting B and T cells [52]. In PCa, how the RNF2 mediated $\mathrm{H} 2 \mathrm{~A}$ ubiquitination is regulated is not known, and further examinations are also needed to find out whether the RNF2 mediated TXNIP repression is dependent on its catalytic activity on the H2A ubiquitylation.

Taken together, our study demonstrated that RNF2 plays an oncogenic function in PCa, and that TXNIP is an important downstream target of RNF2. Because of the high RNF2 level in PCa tumor tissues and the inhibited cell proliferation and increased apoptosis in RNF2 knockdown cells, we conclude that RNF2 may be used as a new biomarker for diagnosis and new target for the therapy of PCa.

\section{MATERIALS AND METHODS}

\section{Immunohistochemistry (IHC)}

Paraffin-embedded tissue microarray (TMA) sections, including PCa tumor tissues $(\mathrm{n}=81)$ and benign prostatic hyperplasia $(\mathrm{BPH})$ tissues $(n=71)$ were subjected to IHC staining to detect the expression level of RNF2. Briefly, slides were deparaffinized in xylene and rehydrated through a graded alcohol series before endogenous peroxidase activity was blocked with $3 \%$ $\mathrm{H}_{2} \mathrm{O}_{2}$. Nonspecific protein binding was blocked using preimmune rabbit serum. The primary antibody for RNF2 (1:1000, Abcam, ab101273) was diluted to recommended concentration and incubated with the sections overnight in a humidified chamber at $4^{\circ} \mathrm{C}$. The sections were washed 3 times with phosphate buffer solution (PBS) before HRP conjugated secondary antibody (Elivision ${ }^{\mathrm{TM}}$ super HRP (Mouse/Rabbit) IHC Kit, KIT-9922, Fuzhou, China) was added and incubated for 30 minutes at room temperature. Visualization was performed using 3,3'-diaminobenzidine (DAB) chromogen for 2 to 3 minutes. The negative control was made by replacing the primary antibody with PBS. Sections were counterstained with hematoxylin. Photos were taken using the Olympus Microscope and DP Controller System (DP70, Japan). RNF2 expression was scored independently by two pathologists blinded to the clinical characteristics of the patients, using H-score method [17]. In brief, the H-score was generated by adding the percentage of strongly stained nuclei $(3 \times)$, moderately stained nuclei $(2 \times)$ and weakly stained nuclei $(1 \times)$, which ranges from 0 to 300 . The tumor grades were classified according to the Gleason score. Tumors with the Gleason score $\leq 7$ were low grade, tumors scored 8 to 10 were designated as high grade.

The DU145 xenograft tumor tissues were fixed in $4 \%$ formaldehyde immediately after resection and then paraffin-embedded. Tumor slides were subjected to immunohistochemical staining of RNF2 (1:1000, Abcam, ab101273), TXNIP (1:1000, CST, \#14715), PCNA (1:200,CST,\#13110) and cleaved caspase-3 (1:50, Abcam, ab32042), following the above procedures.

\section{Cell culture}

PCa cell lines (DU145 and LNCaP) were cultured in complete Roswell Park Memorial Institute-1640 (RPMI1640) medium (HyClone, Logan, UT) supplemented with $10 \%$ fetal bovine serum (HyClone, Logan, UT) and 1\% penicillin-streptomycin (Invitrogen, Carlsbad, CA). All cells were cultured in a humidified incubator at $37^{\circ} \mathrm{C}$ in $5 \% \mathrm{CO}_{2}$.

\section{RNA interference}

For the knockdown of RNF2 or TXNIP using small interfering RNA (siRNA), the following siRNA duplexes were synthesized (Genepharma, Shanghai, China): siRNF2 \#1, sense: 5'-GGCUAGAGCUUGAUAAUAATT-3', antisense: 5'-UUAUUAUCAAGCUCUAGCCTT-3'; siRNF2 \#2, sense: 5'-CCAGUUCACUGUAUUAAAUTT-3', antisense: 5'-AUUUAAUACAGUGAACUGGTT-3'; 
siTXNIP, sense: 5'-GAGACCUGGAAACAAAUA UTT-3', anti-sense: 5'-AUAUUUGUUUCCAGGU CUCTT-3'; siNC, sense: 5'-UUCUCCGAACGUGUCA CGUTT-3', anti-sense: 5'-ACGUGACACGUUCGGA GAATT-3'. SiNC was used as negative control. The siRNA duplexes $(100 \mathrm{nmol} / \mathrm{L})$ were transfected into DU145 or LNCaP cells using Lipofectamine 2000 (Invitrogen, USA) according to the manufacturer's instructions. Cells were harvested 72 hours posttransfection for mRNA or protein analysis.

For the knockdown of RNF2 using shRNA, shRNA-expressing lentivirus vectors were constructed (Genechem, Shanghai, China). The target sequences are: shScr: 5'-TTCTCCGAACGTGTCACGT-3'; shRNF2\#1: 5'-AAGTCTACACAGTGAATTA-3'; sh RNF2\#2: 5'-ACCTACAAAGGAGCACAAA-3'; shTXNIP: 5'-GACTTATACTGAGGTGGAT-3'. The recombinant lentivirus vectors and packaging vectors were cotransfected into $293 \mathrm{~T}$ cells for virus package. Supernatants containing lentivirus expressing RNF2-targeting shRNAs, TXNIPtargeting shRNAs and negative control shRNAs were harvested 3 days after transfection. The lentiviruses were then purified by centrifugation, and the titer was confirmed. DU145 and LNCaP cells were infected with the lentivirus at $20 \mathrm{MOI}$ and $5 \mathrm{MOI}$, respectively.

\section{Quantitative real-time reverse-transcriptase polymerase chain reaction ( $R T-q P C R)$}

Total RNA was extracted using the RNeasy Plus Universal Mini Kit (QIAGEN, Hilden, Germany) according to the manufacturer's protocol. RNA quantity and quality were assessed by NanoDrop 2000 (Thermo, USA). The RNA was reverse transcribed with the Revert Aid ${ }^{\mathrm{TM}}$ First Strand cDNA Synthesis Kit (Fermentas, St. Leon-Rot, Germany) according to the manufacturer's instruction. The RT-qPCR was performed using a CFX96 ${ }^{\mathrm{TM}}$ Real-Time PCR system (BioRad, Valencia, CA) with SYBR Green reagents (\#DRR041A; TaKaRa, Japan) according to the manufacturer's instruction. The RT-qPCR analysis was performed in a total volume of $20 \mu \mathrm{L}$ with the following amplification steps: an initial denaturation step at $95^{\circ} \mathrm{C}$ for 10 minutes, followed by 40 cycles of denaturation at $95^{\circ} \mathrm{C}$ for 15 seconds and elongation at $55^{\circ} \mathrm{C}$ for 30 seconds. Gene expression was normalized to human $\beta$-actin and calculated by the $2^{-\Delta \Delta \mathrm{Ct}}$ method. Primers used for qPCR were as follows: RNF2, Forward: 5'-AGCACAATAATCAGCAAGCACTC-3', Reverse: 5'-GCTCCACTACCATTTTCAATCTG-3'; TXNIP: Forward: 5'-CTTGCGGAGTGGCTAAAGTG-3', Reverse: 5'-TTGAAGGATGTTCCCAGAGG-3'; $\beta$-actin: Forward: 5'-TGGCATCCACGAAACTACC-3', Reverse: 5'-GTGTTGGCGTACAGGTCTT-3'.

\section{Affymetrix microarray analysis}

For the microarray analysis, DU145 cells were transfected with siRNA targeting RNF2. Seventy-two hours after transfection, cells were harvested and total RNA was extracted using the method mentioned above. Total RNA was then subjected to gene expression profiling, using the Affymetrix gene chip array (Biotechnology, Shanghai, China). The gene expression data were logtransformed, median centered and analyzed using the SBC Analysis System (Biotechnology, Shanghai, China).

\section{Western blot}

Whole cell lysates were extracted using RIPA lysis buffer supplemented with protease inhibitor cocktail (Roche, Indianapolis, IN, USA) and quantified by BCA assay. Lysates $(30 \mu \mathrm{g})$ from each sample were separated by $10 \%$ SDS-PAGE and then transferred onto nitrocellulose membranes (Millipore, Bedford, MA). The membranes were blocked in 5\% nonfat milk diluted in TBST (Tris Buffered Saline containing $0.05 \%$ Tween-20) for 1 hour at room temperature before the addition of the appropriate primary antibody for an overnight incubation at $4^{\circ} \mathrm{C}$. Betaactin was used as loading control. Antibodies used in this study were: anti-RNF2 rabbit monoclonal antibody (1:1000, CST, \#5694, Danvers, Massachusetts), anti-TXNIP rabbit monoclonal antibody $(1: 1000, \mathrm{CST}, \# 14715)$ and anti- $\beta$ actin mouse monoclonal antibody (1:1000, Sigma, A5441). The membranes were then washed with TBST and incubated with the appropriate HRP-conjugated secondary antibody for 1 hour at room temperature. The bands were visualized using a chemiluminescence reagent (New England Nuclear, Boston, MA) and photographed by FluorChem FC2 system (Alpha Innotech, San Leandro, CA).

\section{MTT assay}

Cell proliferation in vitro was analyzed using tetrazolium salt 3-(4, 5-dimethylthiazol-2-yl)-2, 5-diphenyltetrazolium bromide (MTT). The DU145 or LNCaP cells were transfected with specific siRNA (siNC, siRNF2 or siTXNIP) for 24 hours or infected with shRNA expressing lentivirus (shScr, shRNF2 or shTXNIP) for 72 hours before MTT analysis. Briefly, 3000 cells of each group were plated in 96-well plates in $100 \mu \mathrm{L} 1640$ medium. For analysis: $20 \mu \mathrm{L}$ of MTT substrate (from a $2.5 \mathrm{mg} / \mathrm{ml}$ stock solution in PBS) was added to each well and the plates were incubated for an additional 4 hours at $37^{\circ} \mathrm{C}$ with $5 \% \mathrm{CO}_{2}$. The medium was removed and the cells were solubilized in $150 \mu \mathrm{L}$ dimethylsulfoxide, and colorimetric analysis was performed (wavelength: $492 \mathrm{~nm}$ ). One plate was analyzed immediately after the cells adhered (approximately 4 hours after plating), and the remaining plates were analyzed every 24 hours for the next four consecutive days.

\section{Cell cycle and apoptosis analysis by flow cytometry}

The DU145 or LNCaP cells were transfected with specific siRNAs (siNC, siRNF2 or siTXNIP) or infected 
with shRNA expressing lentivirus (shScr, shRNF2 or shTXNIP) for 72 hours before analysis. For cell cycle analysis, cells were harvested and washed with ice-cold PBS before being fixed with $70 \%$ ice-cold ethanol. Then, cells were collected by centrifugation and resuspended in PBS containing RNase $(100 \mu \mathrm{g} / \mathrm{ml})$ and Propidium Iodide (PI) $(40 \mu \mathrm{g} / \mathrm{ml}, \mathrm{BD}$ Bioscience, CA, USA $)$ and incubated at $37^{\circ} \mathrm{C}$ for 1 hour. Finally, the cell cycle were analyzed by FACS scan flow cytometer (BD, San Jose, CA, USA) and the relative ratios of $\mathrm{G} 1, \mathrm{~S}$ and $\mathrm{G} 2$ phases were analyzed by Flow Jo 2.8 software. For apoptosis analysis, cells were harvested and suspended in PBS at a density of $1 \times 10^{6}$ cells $/ \mathrm{mL}$, and apoptotic cells were analyzed by CYTOMICS FC 500 flow cytometer (Beckman Coulter) after incubation with reagent containing Annexin V-FITC and Propidium Iodide (PI; BD Bioscience, CA, USA) for 15 minutes in darkness at room temperature.

\section{Xenograft tumor model}

The protocol for animal study was approved by the Ethics Committee of the Fourth Military Medical University (FMMU, Xi'an, China). Athymic Balb/c nude mice (from Laboratory Animal Center, FMMU) were housed in individual ventilated cages at $\left(25 \pm 1^{\circ} \mathrm{C}\right)$ with a 12-hour light/12-hour dark cycle. The use of animals in this study complies with the Guide for the Care and Use of Laboratory Animals (National Institutes of Health publication no. 86-23, revised 1985). Prior to injection, 15 nude mice (5 weeks old, weighing $21.04 \pm 1.38 \mathrm{~g}$ ) were assigned at random into three groups with 5 mice per group (shScr, shRNF2 \#1 and shRNF2 \#2). Different groups of cells were washed and $5 \times 10^{6}$ cells were suspended in $0.2 \mathrm{~mL}$ RPMI-1640 and then subcutaneously injected into the back, near the right thigh of nude mice. Tumor growth was measured by the tumor diameter with a Vernier caliper every 5 days beginning on the 5 th day of injection till the $35^{\text {th }}$ day. Tumor volume was calculated as length $\times$ width $^{2} / 2$, where the length and width are the longest and shortest axes in millimeters.

\section{Chromatin immunoprecipitation (ChIP) assay}

ChIP assay was performed according to previous report with minor modifications [53]. Briefly, DU145 cells were harvested and cross-linked by $1 \%$ formaldehyde for 15 minutes at room temperature. Cells were harvested and resuspended in RIPA lysis buffer in the presence of a protease inhibitor cocktail, then chromatin was sheared by sonication to an average length of 200-1000 base pairs. The sheared chromatin was divided into three groups with equal amount for immunoprecipitation with either anti-RNF2 (CST, \#5694), anti-H2AK119Ub (CST, \#8240) or control IgG (isotype control)(CST, \#2729) with magnetic beads. The immunoprecipitants were eluted, reversed cross-linked, and treated with proteinase $\mathrm{K}$. The purified DNA was subjected to real time quantitative PCR using primers designed based on the region within $1000 \mathrm{bp}$ before the transcription start site of TXNIP. The primers used are as follows: Primer 1: Forward: 5'-TTCCTTTTCCTCCAGAAGCA-3', Reverse: 5'-TTCTACCTGCAAAGTTGGGG-3'. Primer 2: Forward: 5'-CCTCCTATTTCCGTTCCACA-3', Reverse: 5'-TACTTTCAGGTTTGGGGCTG-3'. Primer 3: Forward: 5'-CCTCAGAGACGGTGGTGTTT-3', Reverse: 5'-GGTGTGGACGTTTCTGGTCT-3'.

\section{Statistical analysis}

Statistical analysis was performed using IBM SPSS statistical software (version 20.0). Data were statistically analyzed by Student's t test. P values were determined using 2-sided tests, and $\mathrm{P}$ value $<0.05$ was considered to be statistically significant. All of the results are presented as the mean \pm standard deviation.

\section{ACKNOWLEDGMENTS}

We thank Dr. Tao Wang (Department of Immunology, Fourth Military Medical University, China) for helpful discussion. We thank Mrs. Yunxin Cao and Mr. Jintao $\mathrm{Hu}$ (Department of Immunology, Fourth Military Medical University, China) for flow cytometry analysis. We also thank Dr. Changhong Shi (Laboratory Animal Center, Fourth Military Medical University, China) for the xenograft model experiment.

\section{CONFLICTS OF INTEREST}

The authors declare no conflicts of interest.

\section{FUNDING}

This work was supported by grants from the National Natural Science Foundation of China (No. 81171924, 81372225, 81372771, 81172146).

\section{REFERENCES}

1. Ferlay J, Shin HR, Bray F, Forman D, Mathers C and Parkin DM. Estimates of worldwide burden of cancer in 2008: GLOBOCAN 2008. International journal of cancer. 2010; 127:2893-2917.

2. Mahapatra S, Klee EW, Young CY, Sun Z, Jimenez RE, Klee GG, Tindall DJ and Donkena KV. Global methylation profiling for risk prediction of prostate cancer. Clinical cancer research. 2012; 18:2882-2895.

3. Taberlay PC and Jones PA. DNA methylation and cancer. Progress in drug research. Fortschritte der Arzneimittelforschung. 2011; 67:1-23. 
4. Dawson MA and Kouzarides T. Cancer epigenetics: from mechanism to therapy. Cell. 2012; 150:12-27.

5. Helin $\mathrm{K}$ and Dhanak D. Chromatin proteins and modifications as drug targets. Nature. 2013; 502:480-488.

6. Kelly TK, De Carvalho DD and Jones PA. Epigenetic modifications as therapeutic targets. Nature biotechnology. 2010; 28:1069-1078.

7. Lee TI, Jenner RG, Boyer LA, Guenther MG, Levine SS, Kumar RM, Chevalier B, Johnstone SE, Cole MF, Isono K, Koseki H, Fuchikami T, Abe K, Murray HL, Zucker JP, Yuan B, et al. Control of developmental regulators by Polycomb in human embryonic stem cells. Cell. 2006; 125:301-313.

8. Vidal M. Role of polycomb proteins Ring1A and Ring1B in the epigenetic regulation of gene expression. The International journal of developmental biology. 2009; 53:355-370.

9. Simon JA and Kingston RE. Mechanisms of polycomb gene silencing: knowns and unknowns. Nature reviews Molecular cell biology. 2009; 10:697-708.

10. Sparmann A and van Lohuizen M. Polycomb silencers control cell fate, development and cancer. Nature reviews Cancer. 2006; 6:846-856.

11. Otte AP and Kwaks THJ. Gene repression by Polycomb group protein complexes: a distinct complex for every occasion? Current Opinion in Genetics \& Development. $2003 ; 13: 448-454$.

12. Levine SS, Weiss A, Erdjument-Bromage H, Shao Z, Tempst $\mathrm{P}$ and Kingston RE. The Core of the Polycomb Repressive Complex Is Compositionally and Functionally Conserved in Flies and Humans. Molecular and Cellular Biology. 2002; 22:6070-6078.

13. Kuzmichev A, Nishioka K, Erdjument-Bromage H, Tempst $\mathrm{P}$ and Reinberg D. Histone methyltransferase activity associated with a human multiprotein complex containing the Enhancer of Zeste protein. Genes \& development. 2002; 16:2893-2905.

14. Sparmann A and van Lohuizen M. Polycomb silencers control cell fate, development and cancer. (1474-175X (Print)).

15. Varambally S, Dhanasekaran SM, Zhou M, Barrette TR, Kumar-Sinha C, Sanda MG, Ghosh D, Pienta KJ, Sewalt RG, Otte AP, Rubin MA and Chinnaiyan AM. The polycomb group protein EZH2 is involved in progression of prostate cancer. Nature. 2002; 419:624-629.

16. $\mathrm{Xu} \mathrm{K}, \mathrm{Wu} \mathrm{ZJ}$, Groner AC, He HH, Cai C, Lis RT, Wu $\mathrm{X}$, Stack EC, Loda M, Liu T, Xu H, Cato L, Thornton JE, Gregory RI, Morrissey C, Vessella RL, et al. EZH2 oncogenic activity in castration-resistant prostate cancer cells is Polycomb-independent. Science. 2012; 338:1465-1469.

17. Wu C, Jin X, Yang J, Yang Y, He Y, Ding L, Pan Y, Chen $\mathrm{S}$, Jiang $\mathrm{J}$ and Huang $\mathrm{H}$. Inhibition of EZH2 by chemo- and radiotherapy agents and small molecule inhibitors induces cell death in castration-resistant prostate cancer. Oncotarget. 2016; 7:3440-3452. doi: 10.18632/oncotarget.6497.
18. Fan C, He L, Kapoor A, Gillis A, Rybak AP, Cutz JC and Tang D. Bmil promotes prostate tumorigenesis via inhibiting p16(INK4A) and p14(ARF) expression. Biochimica et biophysica acta. 2008; 1782:642-648.

19. Sanchez-Beato M, Sanchez E, Gonzalez-Carrero J, Morente M, Diez A, Sanchez-Verde L, Martin MC, Cigudosa JC, Vidal $M$ and Piris MA. Variability in the expression of polycomb proteins in different normal and tumoral tissues. A pilot study using tissue microarrays. Modern pathology. 2006; 19:684-694.

20. Li XQ, He WP, Hou WH, Chen JW, Fan RR, Yuan LJ, Yang GP, Cai MY, Chen L, Li J, He SY, Xie D, Yang GF and You ZS. Overexpression of RNF2 is positively associated with ovarian carcinoma aggressiveness and indicative of poor patient survival. Oncotarget. 2016 Apr 25. doi: 10.18632/ oncotarget.8975. [Epub ahead of print].

21. Chen S, Chen J, Zhan Q, Zhu Y, Chen H, Deng X, Hou Z, Shen B, Chen Y and Peng C. H2AK119Ub1 and $\mathrm{H} 3 \mathrm{~K} 27 \mathrm{Me} 3$ in molecular staging for survival prediction of patients with pancreatic ductal adenocarcinoma. Oncotarget. 2014; 5:10421-10433. doi: 10.18632/oncotarget.2126.

22. Li XD, Chen SL, Dong P, Chen JW, Wang FW, Guo SJ, Jiang LJ, Zhou FJ, Xie D and Liu ZW. Overexpression of RNF2 Is an Independent Predictor of Outcome in Patients with Urothelial Carcinoma of the Bladder Undergoing Radical Cystectomy. Scientific reports. 2016; 6:20894.

23. Rodriguez-Paredes $M$ and Esteller M. Cancer epigenetics reaches mainstream oncology. Nature medicine. 2011; 17:330-339.

24. Portela A and Esteller M. Epigenetic modifications and human disease. Nature biotechnology. 2010; 28:1057-1068.

25. Wang W, Qin JJ, Voruganti S, Nag S, Zhou J and Zhang R. Polycomb Group (PcG) Proteins and Human Cancers: Multifaceted Functions and Therapeutic Implications. Medicinal research reviews. 2015; 35:1220-1267.

26. Albany C, Alva AS, Aparicio AM, Singal R, Yellapragada S, Sonpavde G and Hahn NM. Epigenetics in prostate cancer. Prostate cancer. 2011; 2011:580318.

27. Chen Z, Wang L, Wang Q and Li W. Histone modifications and chromatin organization in prostate cancer. Epigenomics. 2010; 2:551-560.

28. Yu J, Rhodes DR, Tomlins SA, Cao X, Chen G, Mehra R, Wang X, Ghosh D, Shah RB, Varambally S, Pienta KJ and Chinnaiyan AM. A polycomb repression signature in metastatic prostate cancer predicts cancer outcome. Cancer research. 2007; 67:10657-10663.

29. Fan C, He L, Kapoor A, Rybak AP, De Melo J, Cutz JC and Tang D. PTEN inhibits BMI1 function independently of its phosphatase activity. Molecular cancer. 2009; 8:98.

30. Lukacs RU, Memarzadeh S, Wu H and Witte ON. Bmi-1 is a crucial regulator of prostate stem cell self-renewal and malignant transformation. Cell stem cell. 2010; $7: 682-693$. 
31. Rai K, Akdemir KC, Kwong LN, Fiziev P, Wu CJ, Keung EZ, Sharma S, Samant NS, Williams M, Axelrad JB, Shah A, Yang D, Grimm EA, Barton MC, Milton DR, Heffernan TP, et al. Dual Roles of RNF2 in Melanoma Progression. Cancer discovery. 2015; 5:1314-1327.

32. Wen W, Peng C, Kim MO, Ho Jeong C, Zhu F, Yao K, Zykova T, Ma W, Carper A, Langfald A, Bode AM and Dong Z. Knockdown of RNF2 induces apoptosis by regulating MDM2 and p53 stability. Oncogene. 2014; 33:421-428.

33. Hu S, Wilson KD, Ghosh Z, Han L, Wang Y, Lan F, Ransohoff KJ, Burridge P and Wu JC. MicroRNA-302 increases reprogramming efficiency via repression of NR2F2. Stem Cells. 2013; 31:259-268.

34. Ridgway JB, Presta LG and Carter P. 'Knobs-into-holes' engineering of antibody $\mathrm{CH} 3$ domains for heavy chain heterodimerization. Protein Eng. 1996; 9:617-621.

35. Su WJ, Fang JS, Cheng F, Liu C, Zhou F and Zhang J. RNF2/Ring1b negatively regulates p53 expression in selective cancer cell types to promote tumor development. Proceedings of the National Academy of Sciences of the United States of America. 2013; 110:1720-1725.

36. Chen KS and DeLuca HF. Isolation and characterization of a novel cDNA from HL-60 cells treated with 1,25-dihydroxyvitamin D-3. Biochimica et biophysica acta. 1994; 1219:26-32.

37. Sheth SS, Bodnar JS, Ghazalpour A, Thipphavong CK, Tsutsumi S, Tward AD, Demant P, Kodama T, Aburatani H and Lusis AJ. Hepatocellular carcinoma in Txnip-deficient mice. Oncogene. 2006; 25:3528-3536.

38. Bryant HE, Schultz N, Thomas HD, Parker KM, Flower D, Lopez E, Kyle S, Meuth M, Curtin NJ and Helleday T. Specific killing of BRCA2-deficient tumours with inhibitors of poly(ADP-ribose) polymerase. Nature. 2005; 434:913-917.

39. Han SH, Jeon JH, Ju HR, Jung U, Kim KY, Yoo HS, Lee YH, Song KS, Hwang HM, Na YS, Yang Y, Lee $\mathrm{KN}$ and Choi I. VDUP1 upregulated by TGF-beta1 and 1,25-dihydorxyvitamin D3 inhibits tumor cell growth by blocking cell-cycle progression. Oncogene. 2003; 22:4035-4046.

40. Butler LM, Zhou X, Xu WS, Scher HI, Rifkind RA, Marks PA and Richon VM. The histone deacetylase inhibitor SAHA arrests cancer cell growth, up-regulates thioredoxinbinding protein-2, and down-regulates thioredoxin. Proceedings of the National Academy of Sciences of the United States of America. 2002; 99:11700-11705.

41. Augustin HG, Koh GY, Thurston G and Alitalo K. Control of vascular morphogenesis and homeostasis through the angiopoietin-Tie system. Nature reviews Molecular cell biology. 2009; 10:165-177.

42. Ikarashi M, Takahashi Y, Ishii Y, Nagata T, Asai S and Ishikawa K. Vitamin D3 up-regulated protein 1 (VDUP1) expression in gastrointestinal cancer and its relation to stage of disease. Anticancer research. 2002; 22:4045-4048.
43. Dutta KK, Nishinaka Y, Masutani H, Akatsuka S, Aung TT, Shirase T, Lee WH, Yamada Y, Hiai H, Yodoi J and Toyokuni S. Two distinct mechanisms for loss of thioredoxin-binding protein-2 in oxidative stress-induced renal carcinogenesis. Laboratory investigation. 2005; 85:798-807.

44. Ahsan MK, Masutani H, Yamaguchi Y, Kim YC, Nosaka K, Matsuoka M, Nishinaka Y, Maeda M and Yodoi J. Loss of interleukin-2-dependency in HTLV-I-infected T cells on gene silencing of thioredoxin-binding protein-2. Oncogene. 2006; 25:2181-2191.

45. Tan J, Yang X, Zhuang L, Jiang X, Chen W, Lee PL, Karuturi RK, Tan PB, Liu ET and Yu Q. Pharmacologic disruption of Polycomb-repressive complex 2-mediated gene repression selectively induces apoptosis in cancer cells. Genes \& development. 2007; 21:1050-1063.

46. Zhou J, Bi C, Cheong LL, Mahara S, Liu SC, Tay KG, Koh TL, Yu Q and Chng WJ. The histone methyltransferase inhibitor, DZNep, up-regulates TXNIP, increases ROS production, and targets leukemia cells in AML. Blood. 2011; 118:2830-2839.

47. Wang Z, Rong YP, Malone MH, Davis MC, Zhong F and Distelhorst CW. Thioredoxin-interacting protein (txnip) is a glucocorticoid-regulated primary response gene involved in mediating glucocorticoid-induced apoptosis. Oncogene. 2006; 25:1903-1913.

48. Wang Y, De Keulenaer GW and Lee RT. Vitamin D(3)-upregulated protein-1 is a stress-responsive gene that regulates cardiomyocyte viability through interaction with thioredoxin. The Journal of biological chemistry. 2002; 277:26496-26500.

49. Saitoh T, Tanaka S and Koike T. Rapid induction and $\mathrm{Ca}(2+)$ influx-mediated suppression of vitamin D3 up-regulated protein 1 (VDUP1) mRNA in cerebellar granule neurons undergoing apoptosis. Journal of neurochemistry. 2001; 78:1267-1276.

50. Billiet L, Furman C, Larigauderie G, Copin C, Page S, Fruchart JC, Brand K and Rouis M. Enhanced VDUP-1 gene expression by PPARgamma agonist induces apoptosis in human macrophage. Journal of cellular physiology. 2008; 214:183-191.

51. Endoh M, Endo TA, Endoh T, Isono K, Sharif J, Ohara O, Toyoda T, Ito T, Eskeland R, Bickmore WA, Vidal $\mathrm{M}$, Bernstein BE and Koseki H. Histone H2A monoubiquitination is a crucial step to mediate PRC1-dependent repression of developmental genes to maintain ES cell identity. PLoS genetics. 2012; 8:e1002774.

52. Frangini A, Sjoberg $M$, Roman-Trufero M, Dharmalingam G, Haberle V, Bartke T, Lenhard B, Malumbres M, Vidal M and Dillon N. The aurora B kinase and the polycomb protein ring1B combine to regulate active promoters in quiescent lymphocytes. Molecular cell. 2013; 51:647-661.

53. Shang $\mathrm{Y}, \mathrm{Hu} \mathrm{X}$, DiRenzo J, Lazar MA and Brown M. Cofactor dynamics and sufficiency in estrogen receptorregulated transcription. Cell. 2000; 103:843-852. 